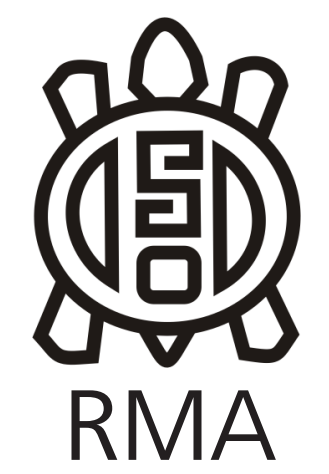

Antropología Social

\title{
Fanáticos y fanatizados: un análisis comparativo sobre las prácticas de consumo y fidelización entre hinchas de un club de fútbol y un grupo de runners
}

\author{
Fanatics and the fanaticized: a comparative analysis of consumption \\ practices and loyalty among football supporters and runners
}

Nemesia Hijós

CONICET, Instituto de Investigaciones Gino Germani, Facultad de Ciencias Sociales, Universidad de Buenos Aires, Argentina.E-mail: nemesiahijos@gmail.com

\begin{abstract}
Resumen
Tomando como punto de partida los estudios sobre fanatismos [fan studies], este trabajo propone una articulación y una aproximación en perspectiva comparativa con el campo de la socio-antropología del deporte a partir de mi trabajo de campo con hinchas de fútbol y corredores amateurs. Analizando mis registros de observación participante, presentaré los diferentes modos en que el mercado y la industria cultural interpelan a los espectadores de eventos futbolísticos como hinchas, socios y/o fanáticos, mientras que algunos practicantes del running son presentados como atletas y/o deportistas, aunque ellos mismos se autodefinen como fanatizados por el deporte. Si bien ser hincha y ser runner pueden ser dos identidades con disposiciones diferentes, frente al contexto contemporáneo y global de mercantilización social, las prácticas de estos sujetos pueden estar asociadas. Es así que mi objetivo es indagar sobre las formas en las cuales el club o la marca interpelan a los actores, proponiendo y prefigurando un modo de ser hincha o un modo de practicar un deporte. Estas identidades construidas están inherentemente ligadas a las formas actuales de consumo (futbolístico y deportivo), las cuales también pueden ser entendidas como resultados de estrategias de fanificación y fidelización al club o a la marca.
\end{abstract}

Palabras claves: fanáticos; fanatizados; running; hinchas; fidelización; consumo.

\begin{abstract}
With a foundation in fan studies, this article proposes an approach which articulates a comparative perspective with the field of socio-anthropology of sport based upon my fieldwork with football supporters and amateur runners. Through an analysis of my participant observation, I will present the different ways in which the market and cultural industry address football spectators as supporters, partners, and/or fans while some runners are presented as athletes, though they define themselves as fanaticized by this sport. While being a supporter or a runner are two identities with different capacities related to the contemporary and global context of social commodification, the practices of these groups may be associated. Thus, my aim is to study how clubs or brands appeal to consumers, proposing and imagining the ways to be a supporter or to practice a sport. These constructed identities are inherently linked to the current methods of consumption (both in football and sport in general), which can also be understood as results of "fanification" and loyalty strategies in regards to the club or brand.
\end{abstract}

Keywords: fanatics; fanaticize; running; supporters; loyalty; consumption.

"Yo los he visto. No están bien de la cabeza. Usan championes con aire y zapatillas de marca, corren descalzos o gastan calzados. Traspiran camisetas, calzan gorras y miden una y otra vez su propio tiempo. Están tratando de ganarle a alguien. Trotan con el cuerpo flojo, pasan a la del perro blanco, pican después de la columna, buscan una canilla para refrescarse... y siguen. Se inscriben en todas las carreras... pero no ganan ninguna. Empiezan a correrla en la noche anterior, sueñan que trotan y a la mañana se levantan como niños en Día de Reyes. Han preparado la ropa que descansa sobre una silla, como lo hacían en su infancia en víspera de vacaciones. El día antes de la carrera comen pastas y no toman alcohol, pero se premian con descaro y con asado apenas termina la competencia. Nunca pude calcularles la edad pero seguramente tienen entre 15 y 85 años. Son hombres y mujeres. No están bien. Se anotan en carreras de ocho o 10 kilómetros y antes de empezar saben que no podrán ganar aunque falten todos los demás. Estrenan ansiedad en cada salida y unos minutos antes de la largada necesitan ir al baño. Ajustan su cronómetro y tratan de ubicar a los cuatro o cinco a los que hay que ganarles. Son sus 
referencias de carrera: 'Cinco que corren parecido a mí. Ganarle a uno solo de ellos será suficiente para dormir a la noche con una sonrisa. Disfrutan cuando pasan a otro corredor... pero lo alientan, le dicen que falta poco y le piden que no afloje. Preguntan por el puesto de hidratación y se enojan porque no aparece. Están locos, ellos saben que en sus casas tienen el agua que quieran, sin esperar que se la entregue un niño que levanta un vaso cuando pasan. Se quejan del sol que los mata o de la lluvia que no los deja ver. Están mal, ellos saben que allí cerca está la sombra de un sauce o el resguardo de un alero. No las preparan... pero tienen todas las excusas para el momento en que llegan a la meta. No las preparan... son parte de ellos...".

Marciano Durán, "Esos locos que corren", 2010

Si alguien me hubiera preguntado a mí cinco años atrás qué tienen en común los hinchas del club de fútbol con los cuales yo estaba haciendo trabajo de campo y los miembros de un grupo de running de la Ciudad Autónoma de Buenos Aires, hubiera asegurado -sin dubitar- que absolutamente en nada se parecen'1. Imaginémonos a un hincha: la representación tal vez estereotipada, homogeneizante y característica que puede aparecer en nuestra mente es la de un hombre fervoroso, luciendo la camiseta con los colores de su equipo, tal vez colgado de un paravalanchas o sujetado del alambrado de un estadio, con su cara queriendo traspasar al campo de juego. Como bien analizaron Pablo Alabarces (2004), José Garriga Zucal (2005) y Verónica Moreira (2005), los cuerpos masculinos de los integrantes de una barra de fútbol suelen ser cuerpos grandes y fuertes, que aguantan el dolor, que habilitan experiencias de la masculinidad, que soportan consumos y abusos de grandes cantidades de alcohol y/o drogas, y que exhiben cicatrices y marcas como resultado de enfrentamientos, combates y peleas. Son cuerpos de grosos, gordos, duros, de gente con aguante ${ }^{2}$. Nada tendrían que ver con los cuerpos atléticos y esbeltos de quienes practican running. Alabarces y Garriga Zucal (2007) mencionan que estas identidades corporales de algunos miembros de las hinchadas de fútbol, de estos pequeños grupos diferenciados del total de los concurrentes a los estadios, forman un nosotros y constituyen otros donde mirarse. Estos cuerpos conforman herramientas que aseguran la identificación con el grupo de pares, porque todos se están viendo estéticamente iguales, con gestualidades similares,

\footnotetext{
${ }^{1}$ Agradezco los comentarios y los aportes realizados por el Lic. Prof. Federico Álvarez Gandolfi a mi ponencia en las Jornadas F.A.NS. (Fanatismo, Academia, Narrativa, Subalternidades), I Jornadas sobre Fanatismo y Cultura de Masas, Representaciones, Prácticas e Identidades, de noviembre de 2016. De dicha presentación surgió un trabajo en coautoría con la Lic. Prof. Daniela Novick para las VII Jornadas de Sociología de la Universidad Nacional de General Sarmiento, en mayo de 2017, que desencadenó en el presente artículo.

2 La cursiva en el cuerpo del texto debe entenderse como una apropiación del discurso de mis interlocutores, términos significativos desde el punto de vista nativo y expresiones de los actores; también es utilizada para resaltar palabras en otro idioma.
}

aunque en el caso de los hinchas lo que va a delimitar el ingreso a un grupo va a ser, en definitiva, la acción y la práctica. Los hechos -más allá de las dimensiones corporales, gestuales, escritas y narrativas- son los que van a establecer si uno pertenece a una hinchada de fútbol o no. En el caso de los runners, también operan representaciones con carácter estereotipado y homogeneizante sobre su identidad: ligadas a un grupo de pares que se reúnen para entrenar o que comparten la pasión por una práctica deportiva y un determinado estilo de vida. Entre ellos circula un ideal de cuerpo que se repite o tiende a aparecer a medida que se observa el ejercicio de esta práctica deportiva: menudos, livianos, con el tren inferior más trabajado (piernas, muslos y glúteos), con músculos no tan grandes ni hipertrofiados, pero sí definidos y marcados.

Al igual que los miembros de una hinchada de fútbol, los corredores construyen una identidad colectiva, que se muestra como homogénea, aunque en el interior exista una heterogeneidad de individualidades. El nosotros de la comunidad runner $^{3}$ no se limita exclusivamente a examinar los aspectos físicos y morfológicos de la mujer o del hombre deportista, sino también en los ornamentos que esos sujetos lucen a través de su cuerpo, como el calzado específico (de acuerdo al tipo de pisada y al terreno donde se va a correr) y la vestimenta técnica (liviana, de secado rápido), los complementos tecnológicos (relojes con GPS para medir la distancia, la velocidad y el recorrido, teléfonos celulares con aplicaciones para registrar la actividad realizada, dispositivos con música motivadora, para correr) y determinados accesorios (como vinchas, gorras, medias de compresión, mochilas y cinturones de hidratación para carreras de distancias más largas). Estos elementos que hacen a la práctica del running contemporáneo configuran determinados cuerpos, discursos y prácticas, al igual que desarrollan una estética particular que se asocia también con el consumo de determinados alimentos y suplementos dietarios (cereales, frutos secos, barras de proteínas, geles deportivos, bebidas isotónicas o batidos), o con el ejercicio de otras prácticas corporales como la musculación, el entrenamiento funcional, la fisioterapia, la natación, el ciclismo urbano y el yoga, las cuales pueden actuar como complemento para un mejor rendimiento de la actividad principal. Aunque dependen de quién esté enunciado en cada caso, las representaciones que hemos construido sobre los hinchas de fútbol y sobre los corredores amateurs, comparten (al menos) un elemento en común: la pasión, sentimiento que moviliza y domina

\footnotetext{
3 La comunidad runner es un sistema heterogéneo en el cual encontramos distintas jerarquías. La gente que corre se ubica dentro del grupo de personas que practica frecuentemente un deporte, se calza unas zapatillas (sin importar mucho su modelo y especificidades) y sale correr por la ciudad. A veces es un sufrimiento para ellos, pero lo hacen porque tienen que hacerlo, por la aproximación del verano o para superar el sedentarismo impuesto por la rutina laboral. De vez en cuando se inscriben en alguna carrera, sólo para demostrar que ellos también pueden. Pero en absoluto son considerados o autodenominados runners, porque aún no han cruzado algunas barreras ni tampoco han superado determinados objetivos.
} 
-con la misma intensidad- la voluntad de estos grupos tan distantes en cuanto a prácticas y modos de ver, elegir y vivir la realidad.

El primer corpus que utilizaré para este análisis comparativo sobre las prácticas de consumo y fidelización es la experiencia que he estado realizando para mi tesis de grado, desde septiembre 2012, con grupos de hinchas, socios, empleados y dirigentes del Club Atlético Boca Juniors (Buenos Aires, Argentina), asociación centenaria pionera en lo que se conoce como sport management ${ }^{4} \mathrm{y}$ reconocida internacionalmente por sus logros deportivos. Preguntas como: ¿cuáles son los sentidos atribuidos a las prácticas económicas en esta institución deportiva? Y ¿Cuáles son las percepciones de los diferentes actores frente a la mercantilización del deporte? son las que guiaron mi trabajo de campo (Hijós, 2014). El segundo corpus a estudiar es lo registrado a partir de la interacción con corredores aficionados y entrenadores pertenecientes al grupo de entrenamiento que la firma Nike auspicia en la ciudad de Buenos Aires (Nike+ Run Club). Habiendo iniciado una nueva investigación sobre prácticas deportivas, asisto regularmente a este running team desde abril de 2016, con el objetivo de comprender el sentido que los corredores le asignan al entrenamiento, sus motivaciones, las representaciones que se construyen a partir del running, y las configuraciones de subjetividades y moralidades contemporáneas, sabiendo que el cuerpo es el elemento central de esta actividad y que el mercado tiene un lugar fundamental para pautar las necesidades vinculadas al consumo, sin olvidar las tensiones entre las disposiciones nativas y las hegemónicas que circulan socialmente.

La pasión por el deporte es lo que estos dos grupos sociales, tanto hinchas de fútbol como corredores amateurs, comparten. Para problematizar mi trabajo de campo, reflexionaré sobre el lugar que puede constituir el consumo en relación a otro tipo de procesos como la conformación de grupos identitarios. Partiré de estos dos casos particulares, los hinchas fanáticos del fútbol y los corredores amateurs fanatizados por el deporte, dado que a propósito del consumo deportivo los actores sociales encuentran espacios en los cuales celebrar su gusto y ponerlo en práctica con otros que comparten sus mismos intereses y con los que también elaboran diversos e importantes sentidos de pertenencia. Así, buscaré interpretar en qué direcciones pueden pensarse identidades conformadas para estos fanáticos/fanatizados a partir de sus respectivas elecciones y consumos.

Pensar identidades en el mundo contemporáneo implica situar y desentrañar modos de significación y configuraciones de subjetividad particulares de la época en la que vivimos. Un modo de abordar esta cuestión es concebir el fenómeno del fanatismo partiendo de la idea de que es un espacio de productividad para aquellos agentes que deciden participar de él. Pero además, se

\footnotetext{
${ }^{4}$ El sport management nace en Europa y refiere a la aplicación de técnicas y estrategias del marketing empresarial, propias de las compañías modernas, a los clubes deportivos.
}

torna necesario incluir otras cuestiones que interroguen y problematicen el fenómeno. En este punto, teniendo en cuenta que las prácticas del fanatismo incluyen algún tipo de consumo, es pertinente preguntarnos cuál es el lugar que éste ocupa. Sin embargo, no es un aspecto que pueda entenderse en términos absolutos y universales. No es lo mismo pensar prácticas de consumo en la época actual que unas décadas atrás. Especialmente en consumos culturales (futbolístico y deportivo), se torna necesario problematizar bajo una óptica contemporánea los modos actuales de producir, circular y consumir. Tal como plantea Bauman (2008), la vida de consumo ya no tiene que ver con adquirir y poseer, sino que la velocidad, el exceso y el desperdicio son las características que definen el consumir actualmente. Se trata de estar en continuo movimiento. Es por esto que frente a estas nuevas lógicas el acto de consumir va mutando. Ya no puede entenderse al consumo como un modo pasivo o como un proceso de satisfacción de necesidades. Como postula Baudrillard, "el consumo es un modo activo de relación (no sólo con los objetos, sino con la colectividad y el mundo), un modo de actividad sistemática y de respuesta global en el cual se funda todo nuestro sistema cultural" (2004, p.223). Siguiendo al autor, el consumo es una actividad de manipulación de signos, en donde los objetos que consumimos se organizan en una sustancia significante que conforma un discurso más o menos coherente. Es decir que en el sistema cultural, el consumo construye parte de nuestra red de vínculos y significaciones.

En la medida en que las personas deben reinterpretar y reorganizar las cosas que han comprado en función de un estilo propio que están construyendo en forma permanente (seguir a un equipo, practicar un deporte, entre otros), el consumo se configura como un acto voluntario y creativo. Sin embargo, esto no implica que sea un acto totalmente racional y libre, un acto de soberanía y dominio sobre el mundo y las cosas. En definitiva, y siguiendo a Sassatelli (2012), aunque se celebre el consumo como acto libre y liberador, y se denigre como acto de imposición y opresor, el acto de consumo es una acción práctica o una serie de actos improvisados llevados a cabo por actores que necesariamente deben moverse en el mundo sistematizado de los esquemas y las imágenes colectivas. A partir del supuesto de que no hay públicos ni sujetos totalmente pasivos ni absolutamente resistentes, propongo indagar sobre el consumo cultural como un espacio para pensar (García Canclini, 1995), teniendo en cuenta las mediaciones y los intersticios que se producen a la hora de poner en contacto al producto con sus públicos (Martín-Barbero, 1983).

\section{Clics modernos: la mercantilización de la pasión en el fútbol}

"El reto del marketing en el fútbol no es hacer aficionados, es hacer que éstos compren cosas" Ferran Soriano ${ }^{5}$

\footnotetext{
5 Empresario, consultor y ejecutivo español, desde septiembre de
} 
Para analizar el fenómeno sociocultural de lo que se denomina fanificación de las audiencias, Libertad Borda utiliza la metáfora de un fondo de recursos diversos y, en este sentido, plantea que:

El fanatismo se ha convertido en un verdadero fondo de recursos -que integra prácticas, actitudes, expectativas y modos de relación y comunicacióndisponible para la construcción de identidades colectivas e individuales, tanto duraderas como fugaces, concepto que podría poseer la flexibilidad necesaria para abarcar las diferentes maneras en que se manifiesta el fenómeno en la actualidad. (2012, p.1)

Este fondo de recursos diversos tiene diferentes componentes que ayudan a pensar el fanatismo a partir de la configuración de identidades (individuales o colectivas, contingentes o duraderas, autonominadas o nominadas externamente); la construcción de comunidades (en donde cabe destacar la formación de redes de reciprocidad); la productividad; el intercambio de bienes materiales y simbólicos; modos de recepción que están caracterizados por la regularidad, la reiteración, la exhaustividad, la proximidad emocional; la defensa intensa del objeto cuando éste es atacado; entre otras.

El trabajo de campo con hinchas, socios y simpatizantes me permitió acercarme a diferentes relatos sobre lo que representa Boca Juniors para estos actores, quienes me explicaron que el club está vinculado a valores como la pasión, el amor y el sentimiento, y también con manifestaciones como llanto, alegría y emoción que el fútbol mismo les provoca, que los caracteriza y los diferencia de otros hinchas. Algunos también me comentaron -tal vez como usualmente sostienen fanáticos de otros clubes- que el hincha de Boca es diferente a los demás, es muy especial, muy fanático, tiene mucho sentimiento, e incluso que lo que sienten por el club es algo que no se puede explicar con palabras, sólo se siente con el corazón, es algo tan fuerte que no se puede comparar con nada, y ese fanatismo implica para ellos, sin lugar a dudas, múltiples sacrificios especialmente económicos- ofrecidos en su nombre. Ese aguante es lo que los moviliza, que los hace viajar a todos lados por más que llueva y truene, por más que se case una hermana, que se accidente un primo, que se reciba un amigo o que sea el día de la madre, aun así, van a la cancha, ya que el domingo hay que ir a ver a Boca, eso no se discute. En cada encuentro con estos grupos de "hinchas militantes" (Moreira, 2006), ellos destacaban su afecto y sentimiento hacia la camiseta, los colores, las banderas, el barrio, el estadio, los jugadores históricos, algún director técnico exitoso e incluso los demás integrantes de la hinchada u otro símbolo que marque una fuerte asociación entre su identidad futbolística o su pertenencia barrial. Por ello, cuando los hinchas

2012 ejerce como director ejecutivo del Manchester City F. C. Fue vicepresidente económico del Fútbol Club Barcelona (2003-2008) y presidente de la aerolínea Spanair en 2009. se refieren a los elementos que hacen a su identidad como grupo -algunos de los cuales son considerados sagrados-, utilizan adjetivos y verbos que indican expresión de un deseo y pertenencia, identificándose como un nosotros cohesionado, enunciado en sus diálogos y expresado en sus canciones. Las prácticas, los símbolos y los lugares van a conformar la identidad social de los hinchas del club. Moreira (2010) sostiene además que los valores que nutren las identidades sociales en los clubes permiten que los actores, "pese a las derrotas y las posiciones inferiores, se autodefinan como 'los mejores'" (p.9). En este sentido, también la lealtad, la fidelidad, el amor y el sentimiento verdadero los llevan a tolerar resultados deportivos adversos o rachas negativas futbolísticamente, porque el hincha de Boca es diferente, no es como las gallinas ${ }^{6}$, que cuando no salen campeón, las tribunas están vacías.

La palabra hincha significa "tener determinados valores y estar en oposición a los políticos, es decir, a los dirigentes y a los socios aspirantes a serlo" (Moreira, 2008, p.118). Así es como se construye nuestra representación: aquel fanático del club que cuenta con la pasión como un recurso y un patrimonio que define su identidad, y que además hace sacrificios en su nombre. Estos hinchas se posicionan en un lugar diferente frente a los integrantes de la barra brava (que sin bien pueden sentir pasión por el club, ese sentimiento estaría atravesado por un interés económico) y a los dirigentes, quienes persiguen un rédito meramente político. La mayoría de los hinchas con los que conversé no manifestaron explícitamente formar parte de alguna agrupación política, sino que -por el contrario- se identificaron como hinchas independientes, que siguen a Boca a todas partes $\mathrm{y}$ quieren lo mejor para el club, siempre. En las entrevistas y conversaciones informales, estos interlocutores caracterizaron sus sentimientos incondicionales hacia el club asociándolos con fanatismo, lealtad, fidelidad y amor, mismas virtudes a las que recurrió Mauricio Macri para justificar su deseo de ser presidente de Boca Juniors durante la campaña electoral en 1995. Se presentaron como hinchas comunes, ya que la mayoría manifiesta no tener vínculos con la dirigencia ni con la barra. Son fanáticos que se alegran, sufren o lloran por el club, y que no esperan nada a cambio por seguir al equipo, sino que hacen sacrificios personales por el amor que tienen frente a esos colores, por la pasión y el sentimiento que quieren seguir transmitiendo a sus hijos. Uno de ellos es José7, publicitario de 32 años, vive en la Ciudad Autónoma de Buenos Aires y es socio activo de Boca. Empezó a ir a la cancha con frecuencia desde el 2003 y hace más de seis años que va con un amigo a la tribuna

\footnotetext{
6 Los hinchas rivales suelen utilizar este término para apodar despectivamente a los hinchas del Club Atlético River Plate. El origen de este apodo está ligado a la época comprendida entre los años 1957 a 1974 o 1975, en los cuales el club tuvo poca consagración en éxitos deportivos.

${ }^{7}$ Los nombres de las personas han sido modificados para preservar el anonimato de quienes formaron parte de la investigación, con la excepción de las figuras públicas.
} 
de La 12. A pesar del amor que tiene por el club, no se enceguece por el fanatismo y es crítico: reconozco que el trato al hincha es de cliente y no de socio, $y$ el club, como el fútbol, es un negocio y una empresa multinacional, pero a pesar de todo, la pasión existe y Boca para mi es un sentimiento. Si bien José es un hincha apasionado, es consciente de que el club se ha mercantilizado desde hace ya algunos años: la gestión de Macri fue la más gloriosa porque se tomaron, en su mayoría, buenas decisiones, aunque también convirtió a la institución en una empresa. Macri marcó el inicio de esta renovación en Boca, tomando como ejemplo a los clubes europeos. La continuidad del plan modernizador fue implementada por las tres gestiones posteriores, especialmente con la de Daniel Angelici, quien hizo hincapié en fortalecer la marca Boca y su posicionamiento internacional, mientras desarrollaba programas de acción social en el barrio para incrementar su imagen como dirigente, manteniendo una fuerte estrategia de comunicación, pero ocultando -como ha pasado en otras gestiones- relaciones menos legítimas como las que establece con la barra (denunciadas por dirigentes y miembros de agrupaciones políticas opositoras).

¿Qué significa para los hinchas que el club haya sido transformado en una empresa? Algunos de ellos lo ven como algo positivo y el cambio lo perciben en hechos como la apertura de mercados en Asia y en la construcción del Museo de la Pasión Boquense, ya que esto significó cambiar la imagen del viejo Boca a la vidriera mundial, comercializando todo lo que antes era amateur. En definitiva, el club se hizo una institución modelo, una boutique. Pero el hecho de que Macri haya sido presidente de Boca no es algo aleatorio, José dice que él, al igual que todos los dirigentes, es un pseudo hincha que tomó decisiones pensadas para un cierto estrato social del club y en función de sus intereses personales. Así, el dirigente aparece como la alteridad de este tipo de hincha fanático. $Y$ es en este punto donde han coincidido mis interlocutores: aunque ven positivos muchos cambios y logros deportivos, no sienten que hayan sido para todos los sectores por igual, manifestando alguna diferenciación de clase en estas decisiones implementadas por el modelo modernizador. José asegura que los dirigentes no piensan en la popular, donde están los socios mayoritarios, sino que sólo se enfocan en mejorar y cuidar las comodidades del target con alto poder adquisitivo, señalando como ejemplo el ingreso de los hinchas a la tribuna durante los partidos: son miles de personas entrando en vallas de un metro de ancho y largas cuadras de cola, en cambio los plateistas entran cinco minutos antes de cada partido... hay diferencia. El relato de José se enmarca en el postulado de Richard Giulianotti (2012), cuando retoma a Ian Taylor (1971), para indicar que el espectáculo futbolístico se ha ido mercantilizando, en busca de un público adinerado que frecuente los partidos. Si bien los trabajadores y miembros de las clases populares han sido considerados parte de una cultura participativa en los clubes de fútbol, hoy se requiere darles nuevos valores a estos espacios recreativos para poder competir con otros elementos culturales de consumo, atrayendo otros actores sociales que quieran consumir productos ligados a su merchandising.

En el contexto de una mercantilización deportiva, los dirigentes de los clubes de fútbol han tenido como objetivo transformar aquellos fanáticos en fieles consumidores. Cuando los éxitos y logros deportivos acompañan, no resultaría algo difícil de implementar, ya que los hinchas van a seguir pagando y queriendo formar parte de todo lo que despliega el club, pero el inconveniente se puede presentar cuando esos logros deportivos no llegan y la masa de hinchas no está conforme con el rendimiento del plantel. Esta es la perspectiva más marketinera. Puede suceder que el equipo tenga un mal rendimiento futbolístico y haya más socios y más compras, ya que desde la gestión del club se intenta reforzar los lazos identitarios para generar apoyo ante las adversas situaciones deportivas. En escenarios como estos el peso estará puesto en las estrategias impulsadas desde la gestión y diseñadas por los especialistas, para conseguir posicionarse fuerte públicamente. En el caso de Boca, la nueva gestión se encargaría de imitar los criterios organizacionales provenientes del exterior: administrando los clubes deportivos con valores de lucro, complementado los compromisos de solidaridad y contención social a partir de los cuales se fundaron estas instituciones, e insertándose en la lógica de funcionamiento del fútbol internacional, cada vez más mercantilizada. Pero para ello necesitarían respaldo en la contraparte, la existencia de un hincha-consumidor que acredite su pasión por el emblema y los colores en la compra, manifestada en el consumo de los bienes ofrecidos. En este sentido, el consumo pasa a ser uno de los mecanismos de legitimación de la pasión del hincha, donde se refleja su fidelidad. El hincha va al estadio, pero no solamente a ver el partido que se disputa, sino que consume diferentes productos: desde comidas rápidas y bebidas en los bares cercanos, puestos callejeros o en la confitería de la cancha, camisetas, gorras, banderas y merchandising oficial y no oficial, hasta llegar a visitar el museo de la institución. Así, para el dirigente, el hincha legitima su pasión en la adquisición de todos los productos y servicios que se comercializan utilizando la imagen del club, desde la camiseta y la indumentaria oficial, pasando por accesorios de todo tipo, hasta la tarjeta de crédito xeneize y la Expo Boca. El sector directivo no tiene que crear ni construir el público seguidor, porque ya cuenta con una gran masa de hinchas incondicionales del equipo, sobre la cual trabaja y desarrolla la aplicación de estrategias de fidelización y consumo a partir de ese fanatismo. En este terreno, Boca es considerado el ejemplo pionero de modernización en el fútbol argentino ya que sus dirigentes buscaron la acumulación de una serie de factores atrayentes para realizar negocios rentables y aumentar el volumen de su 
capital económico y simbólico.

A través de las nuevas tecnologías de la información y comunicación, el fútbol se convirtió en "una práctica cultural dominante a escala global durante la década del noventa" (Villena Fiengo, 2003, p.257) y -si bien el club ya logró posicionarse dentro de las instituciones deportivas más destacadas del mundo- el plan de marketing no se retiró, sino que ha cobrado más notoriedad. En una entrevista de campo, Sebastián (empleado del Departamento de Marketing) hizo mención a esta situación, marcando el énfasis que intentan hacer para no dejar de beneficiar al socio:

(...) nosotros trabajamos, pero vendemos el evento, en realidad... el venir a la cancha un día de partido no es solamente un partido, sino que hay muchísimas más cosas que lo rodean y lo que intentamos hacer siempre es promociones, o dar beneficios, mismo con nuestros sponsors, a veces hacemos fotos en el campo de juego, hacemos los partidos en el entretiempo, aunque ahora frenamos con los partidos porque el cuerpo técnico no nos deja porque nos pidió que cuidáramos un poco más el campo de juego.

El punto concreto de la discusión gira en torno a seguir incorporando (o no, según consideraciones de algunos hinchas) diferentes estrategias modernizadoras que generen ingresos para la economía de Boca. Los relatos del actual presidente Daniel Angelici y de los dirigentes y empleados del Departamento de Marketing y Gestión Comercial se ubican dentro de los defensores del modelo modernizador, proponiendo explotar algunas potencialidades y aspectos del club para generar nuevos recursos. Los discursos de estos especialistas destacan la capacidad priceless que tiene Boca, asociando al club con cosas que no tienen precio, haciendo referencia al simbolismo del sentimiento que puede sentir un hincha de un club de fútbol. Para los hinchas fanáticos, la pasión es algo que no tiene precio en ningún plano económico. ¿Y qué es lo que no tiene precio para un hincha o socio de Boca? Ganar un campeonato o la Copa Libertadores de América pueden ser sus aspiraciones máximas, como me han mencionado varios fanáticos en encuentros casuales. Eso es algo que no tiene valor económico ni precio monetario, pero sí tiene un alto nivel simbólico porque para ellos significa algo. Si bien pueden existir épocas de magros resultados deportivos, para los hinchas lo más importante va a seguir siendo Boca, más allá de los logros alcanzados o no. Ese amor es el que no tiene precio. El empresario o dirigente del club puede aprovechar esta relación de fanatismo y transformarla en la obtención de una ganancia, en la generación de algo rentable vendiendo pasión, generando consumo de un bien intangible y constante, que genera una lealtad y afinidad que se va a mantener para siempre, porque la identidad que uno asume cuando se define como hincha de un club es para toda la vida (salvo algunas excepciones) y por eso, si bien puede comprar más o menos de acuerdo a sus condiciones, va a sentir el deseo constante de hacerlo.

Es así que ya no resulta nada extraño ver mercantilizada la pasión: puede ocurrir que el club no consiga logros en el plano deportivo (que, en definitiva, es lo que persiguen los hinchas) pero sí los alcance en el plano económico. Hoy parece no ser una amenaza la alianza del club con distintas empresas, muy por el contrario, se ve este alcance privatizador y globalizador como una forma exitosa para solucionar los problemas económicos del fútbol. Y, aunque la modernización genere ganancias, se está ante la perspectiva de una refundación del club basada en principios diferentes a los del primer estatuto social, que establecían la gestión colectiva y defendían los fines comunitarios. Queda claro que estas empresas (o estos empresarios) con los que se establecen alianzas estratégicas, planes y programas modernizadores, se pueden apropiar de la explotación parcial y momentánea de la imagen de Boca, pero resultará muy difícil adueñarse de un patrimonio simbólico exclusivo de los hinchas: la pasión. Esta pasión, tal como sostienen ellos, es una de esas cosas que no tienen precio, algo que se lleva adentro, y sobre la cual se trabaja y se apela desde los sectores de marketing y de gestión comercial para incentivar el consumo de productos y servicios ligados a la marca del club.

\section{Crecer bajo presión: el fanatismo en el running}

A diferencia del fútbol que ha logrado expandir su popularidad y masividad desde principios del siglo $X X$, el running es una de las prácticas atléticas con más crecimiento en los últimos años. Si bien podría decirse que siempre ha existido, que nadie lo inventó porque desde su larga progresión hacia el Homo Sapiens los antepasados del hombre ya corrían en busca de su alimento, cazando presas o bien huyendo de los peligros, la organización de grupos de corredores, la planificación de carreras y la extensión de esta práctica es un movimiento que se ha intensificado aún más en la última década. Se puede suponer que, al ser un deporte individual, que (a simple vista) no se requiere de muchos recursos o formación para practicarse y que tiene impactos positivos casi inmediatos sobre la salud, tal vez por eso genere cada vez más adhesión. Pero, ¿qué hacen esos locos que corren? ¿Qué es lo que los lleva a salir temprano en la mañana, a insolarse en pleno verano o a resfriarse en el invierno? ¿Qué satisfacción encuentran en viajar doscientos kilómetros para correr 10 ? ¿A quiénes les quieren ganar? ¿Cuál es el motivo por el cual hoy no nos resulta extraño ver más de 10.000 personas congregadas los fines de semana en los barrios de Palermo o Puerto Madero, pasando por el Obelisco, con el sol quemando en sus espaldas, tratando de mantener un ritmo colectivo pisada tras pisada? Bajo este panorama, los corredores amateurs siguen rutinas de entrenamiento más o menos exigentes, un culto a 
la vida fitness con un creciente respeto por el cuerpo. Porque no se trata sólo de cumplir el objetivo, de cruzar la línea de llegada, de obtener la medalla de la carrera, sino de llegar entero, habiendo disfrutado del recorrido y del esfuerzo.

En esta planificación de estar apto para poder alcanzar la meta, no sólo tienen lugar en el debate la medicina, la educación física y la nutrición: actualmente el mercado se presenta como una voz autorizada más, para decir quién puede correr, cómo, cuándo, por qué y con qué debe hacerlo. Y esto es lo que nos ha llevado a dejar de pensar en la idea de salir a correr como algo pasajero, simple y espontáneo, para reformularlo en sumarse a un grupo de running. Las industrias deportivas usufructúan este panorama y pautan que para salir a correr uno necesita un calzado especial según su pisada, un short liviano y una remera Dri-FIT. O que para sumarse a la comunidad runner uno precisa un complemento tecnológico como el Ipod, con una aplicación determinada que le simplificará la planificación de sus ejercicios, la lista en Spotify con música motivadora o el reloj deportivo Garmin para contar los kilómetros recorridos y el ritmo de la carrera. Las marcas no sólo han desarrollado elementos para el corredor, sino que también han generado la necesidad en ellos, lo que los lleva a creer que requieren de tales elementos para realizar este deporte.

El running es un producto, un resultado más de las estrategias de marketing. El contexto de globalización y el capitalismo sentaron las bases para que el mercado haga rédito de esta práctica deportiva y la transformara en un escenario de consumo, plausible de ser exponenciada cada día más. Nike es una de esas grandes marcas deportivas que compite por instalarse como referente en la indumentaria y el calzado adecuado para los corredores, siendo una de las primeras empresas en organizar masivas carreras de calle. Los primeros eventos organizados por la marca en nuestro país recorrían distancias de 10 kilómetros, con circuitos que rodeaban los lagos de Palermo y Puerto Madero, contando con 3.500 corredores en su primera edición en 2001 y llegando a quintuplicar esa cifra en los últimos años. Con la masificación de esta práctica y la amplia cantidad de inscriptos a estos eventos, Nike buscó alejarse de lo ya popularizado para distinguirse y marcar la diferencia. En cuanto a las carreras, la empresa optó por distancias más largas y otras destinadas sólo al sector femenino, núcleo decisivo en el consumo de su indumentaria. Como no pretende ser meramente una compañía internacional, sino un movimiento, con un modelo de gestión descentralizado y participativo, creó una plataforma de entrenamiento presente también en otras ciudades del mundo y más ambiciosa que el funcionamiento de cualquier running team.

El Nike+ Run Club (simplificado con la sigla NRC y popularizado a través de las redes sociales con el hashtag \#NRCBUE) llegó a Buenos Aires en octubre de 2015 y desde ese momento no dejó de crecer, impulsando a que los corredores se involucren en un ámbito formalizado de sesiones de entrenamiento, eventos y competencias. En Buenos Aires, la actividad se centraliza en el vistoso local que tiene la marca en el Alto Palermo shopping. La localización de este moderno centro comercial en el barrio de Palermo, hace que sea un centro de encuentro y referencia de la ciudad, hecho que seguramente impulsó a los responsables de Nike en Argentina a establecer la acreditación, registro y salida de las actividades deportivas desde dicho espacio. Entre las particularidades que encontré durante la fase exploratoria del trabajo de campo, estableciendo comparaciones con otros running teams, no es sólo que se estaba repitiendo una escena que usualmente se presenta en un gimnasio (dejar el bolso en un locker, saludar a los entrenadores, intercambiar conversaciones con compañeros) -pero dentro de uno de los centros comerciales más convocantes y distinguidos de la ciudad porteña-, sino que las actividades eran totalmente gratuitas. Si bien existen cupos limitados para realizar el entrenamiento, porque se requiere inscripción previa a través de la página web o por medio de la aplicación de la marca, uno está yendo a entrenar de forma supervisada por profesionales, cuatro veces a la semana, sin pagar absolutamente nada. Además, después de cada sesión, los corredores reciben una botella de Gatorade y las fotos del entrenamiento en su correo electrónico. Aunque la práctica deportiva supervisada por profesionales contratados por Nike no tiene costo económico para quienes asisten, esto no significa que no exista un tipo de contrato tácito o inconsciente que lleve a los sujetos a realizar algo a cambio, en calidad de tributo y/o fidelidad a la marca. Son estos mismos corredores amateurs los que realizan publicidad gratuita luciendo indumentaria Nike, utilizando la aplicación para dispositivos móviles y operando como propagadores a partir de la súper exposición que hacen en las redes sociales mencionando a la empresa.

Los entrenadores de Nike+ Run Club están identificados y jerarquizados como pacers y coaches. Los pacers (en castellano, "liebres") son los encargados de marcar determinado ritmo al grupo durante cada sesión de running, ya sean carreras de media o larga distancia, o pasadas de velocidad. Seguir al pacer es toda una garantía de éxito para cualquier runner. Según mi relevamiento, NRC Buenos Aires cuenta con 30 pacers, equilibrada cantidad de mujeres y hombres, que son supervisados por los coaches (instructores): "Toto" y Sebastián, quienes reciben las pautas desde la sede central de la empresa, ubicada en Oregon, Estados Unidos. "Toto" es ex atleta y Profesor de Educación Física, aparenta unos jóvenes 50 años, tal vez porque emana naturalmente su espíritu de líder carismático, definido por los mismos corredores como un motivador nato, capaz de impulsar a quienes se suman por el desafío del primer kilómetro como a quienes buscan bajar sus tiempos. Sebastián, un tanto más joven, tiene un perfil menos histriónico y social, siendo su función más de comunicador de las actividades 
y sesiones especiales, como de los aspectos técnicos previos y posteriores al ejercicio. Pacers y coaches utilizan indumentaria con colores flúor que los identifica y que al mismo tiempo es universal (incluyendo leyendas en el idioma inglés), porque es la misma en las 43 ciudades del donde actualmente hay un NRC.

En una de las paredes del local de Nike en el Alto Palermo está grabada la frase: Tenés un cuerpo, sos un atleta. Conversando con mi preparador físico del gimnasio, me dice que eso no es una condición para que una persona sea corredora: quienes tienen sobrepeso, antecedentes cardiovasculares y de presión, problemas en las articulaciones, los que se están rehabilitando de una lesión, no pueden hacerlo. Pero el objetivo de NRC es no dejar a nadie afuera: uno tiene un cuerpo, es un atleta, puede entrenar y correr, y por ende también debe ser responsable de lo que pase o pueda hacer con él. Esto me hace pensar en la disertación de Guillermo Tofoni, CEO de World Eleven, sobre la activación de marcas en el deporte:

Hoy ya no alcanza con aparecer como sponsor en una camiseta o en la estática de un estadio... La gente está buscando experiencias, tenemos que llevar lo profesional a la gente común, utilizar el producto a nivel motivacional para que las marcas puedan ofrecer sus productos. La industria está a punto caramelo para poder potenciarla, con las redes sociales, porque el negocio del futuro para las marcas es involucrarse.

La disertación de Tofoni fue en el marco del Primer Congreso de Fútbol en Argentina, realizado en octubre de 2016, organizado por un grupo empresarial con experiencia en eventos masivos y corporativos, que proponía reunir una serie de referentes del mundo futbolístico y del management deportivo. El evento tuvo lugar en el lujoso Hotel Hilton de Puerto Madero, donde durante dos días desfilaron directivos de importantes empresas, coaches, ejecutivos y dirigentes de los clubes argentinos de renombre, para brindar su visión estratégica y tendencias a nivel mundial. Estas palabras me llevan a reflexionar sobre la gratuidad de los entrenamientos de Nike, en los eventos y sesiones especiales que organiza la marca, en lo que brindan y lo que consecuentemente generan en los entrenados. Ser parte de este running team es claramente vivir la experiencia de entrenar con ellos. Así, la pertenencia al NRC no sólo implica asistir a las sesiones de entrenamiento y a ciertos eventos especiales organizados por la marca, donde uno puede ser invitado, sino también hacer uso de la aplicación para celulares y dispositivos, y participar así de una comunidad global de corredores. Antes y después de cada sesión, los coaches indican hacer seguimiento del progreso de nuestra actividad deportiva mediante esta herramienta, porque ahí se dan los detalles como ritmo, distancia, rutas y récords personales, con precisión, para tener control, viendo lo que uno quiere saber durante la carrera. La aplicación permite compartir imágenes de las carreras, editarlas y agregar lemas (slogans) de Nike para luego ser posteadas en las redes sociales con hashtags de la comunidad runner. Y esta posibilidad tiene una extendida adhesión entre los entrenados, quienes llenan las redes sociales (particularmente Facebook e Instagram) con sus fotografías (individuales o grupales) inmediatamente después de recibir las fotos de la sesión anterior. Los comentarios debajo de los posteos suelen aparecer segundos más tarde, de forma automática, por parte de otros miembros del NRC, haciendo alusión a las dificultades de la última sesión de entrenamiento, felicitaciones por el rendimiento del grupo y/o saludos de aliento de algún compañero que haya estado ausentado durante los últimos días. Esto da cuenta que el ciberespacio es un lugar importante para este tipo de grupos de pertenencia porque nos encontramos en un "paradigma comunicacional" (De Moraes, 2010) que ha ampliado los sistemas, lenguajes y medios de circulación de consumo a partir de la digitalización. Sin embargo, no se trata de "comunidades de guardarropa" (Bauman, 2008), es decir, de comunidades ilusorias que uno siente que integra por el hecho de estar donde hay otros presentes o por lucir símbolos o gustos compartidos. En este caso hay un permiso de entrada, reglas y prácticas preestablecidas que definen identitariamente al grupo. Aunque el ciberespacio es crucial, éste se ve retroalimentado también por otro tipo de espacios en donde se desarrollan prácticas diferentes, como las carreras, las competencias, los días de fondo y las salidas grupales.

Una persona ajena a este entorno, que escucha lo que un corredor gasta en unas zapatillas, en un reloj con velocímetro y cuentakilómetros, incluso lo que le cuesta la inscripción a una carrera, puede considerar un despilfarro la cantidad de dinero depositado en esas elecciones. Los que no forman parte del mundo runner o no han practicado de forma inicial este deporte, alguna vez han dicho: hay que estar loco para gastar tanta guita en un par de zapatillas, con todas las que tienen, hay tantas cosas que son más importantes. Si bien puede ser que no sientan envidia por las zapatillas o el reloj en sí, consideran que se podría hacer algo mejor con ese dinero. En una de sus obras más importantes, Bourdieu (1979) dice que nunca es realmente posible ponerse en el lugar de los que están situados en el otro extremo del mundo social porque "la locura de unos es la necesidad primera de otros". Para los runners, muchos de estos gastos considerados ostentosos, no tienen nada que ver con el despilfarro, sino que son casi siempre una excelente inversión que les permite acumular prestigio, distinción y más redes de conocidos. Este sistema de necesidades que rodea al que ya lleva un tiempo corriendo, se explica como una coherencia de elecciones propia de su condición, de su estilo de vida runner.

De acuerdo a lo que los corredores me han dicho, uno se consagra cuando termina una maratón, esa experiencia 
los convierte en verdaderos corredores, distinguidos, honorables, de otra categoría. La maratón de Buenos Aires, por ejemplo, funciona como un gran rito de pasaje que los transforma y los consolida en runners. Aquellos que la hicieron, primeramente, se sumaron a un running team, empezaron a conocer las claves para mejorar el rendimiento (como entrar en calor apropiadamente y elongar después del ejercicio) y a complementar con hábitos de alimentación saludable (como ingerir bebidas isotónicas post-entrenamiento, comer hidratos de carbono la noche previa a la carrera, no tomar alcohol). Así, quienes participan de estos equipos van incorporando de a poco la información que reciben e intentando cambiar hábitos considerados negativos. Si bien es un proceso que requiere de tiempo y disciplina, a medida que van notando mejoras en su productividad y estado de salud, se retroalimentan con la motivación necesaria para seguir modificando sus conductas. Algunos me comentan que el running está en sus genes, que es un impulso irrefrenable, que se les ha vuelto una adicción, que ya no conciben su vida sin salir a correr, porque están fanatizados por este deporte. Y mientras recrean su espíritu corriendo, el mercado se infiltra paulatinamente, los rodea con las marcas ligadas al deporte. El runner hace uso de ellas, las transforma en herramientas para mejorar su rendimiento, para controlar su actividad y así superarse. Si bien el running es una tendencia masiva, no todos los que la practican comparten los mismos sentidos, hay quienes se fanatizan, no sólo con el entrenamiento sino también con el consumo de todo lo que la industria les ofrece.

Vení a correr con nosotros es el lema utilizado por Nike, divulgado por los pacers, entrenadores y coaches de la compañía deportiva a través de las redes sociales, incluso exhibido en la estática del local, que invitan a que más personas se unan al running team. Pero no es meramente un grupo de personas que entrenan o salen a correr. Esta plataforma de entrenamiento es parte de una comunidad mundial de running, que orienta a sus corredores, les brinda planes de entrenamiento, sesiones especiales, hidratación y acceso a determinados productos, al mismo tiempo que promueve su filosofía, misión y visión empresarial. ¿Cómo estos corredores devuelven o saldan esta formación gratuita? Con homenaje -a través de los hashtags alusivos en las redes sociales-, respeto y fidelidad en el consumo, es decir, con culto a la marca y fanatización.

\section{Consideraciones finales}

El deporte, más allá de la actividad reglada y competitiva que incluye la actividad física, actualmente es una de las principales mercancías massmediáticas desde donde se estructuran ciertas representaciones y se planifican determinados consumos. Es así que el alcance y el éxito de un determinado deporte obedece en muchos aspectos a la imagen que las grandes marcas, legitimadas por la lógica mercantil, proponen y construyen sobre esa práctica deportiva, orientada hacia distintos grupos sociales. Asimismo hay que reconocer que el deporte no es un mundo encerrado en sí mismo, sino que influye y se influye por prácticas, ideales y jerarquías sociales, culturales y de consumo. Es decir, el deporte es consumido por un público -como espectador y/o participante-, es promovido por entidades cuya finalidad es el lucro, además de la publicidad mediática que se debe diseñar para incentivar un escenario de oferta y demanda en relación al contexto nacional.

El avance de la lógica mercantil en el campo deportivo ha tenido como derivación que en la actualidad se esté debatiendo transformar el histórico modelo jurídico de los clubes argentinos (asociaciones civiles sin fines de lucro) en sociedades anónimas deportivas (SAD), para resolver la corrupción, las administraciones ineficientes y la violencia en el fútbol, al mismo tiempo que se aplican estrategias características del proceso de modernización en los estadios, remodelando y/o construyendo arenas polivalentes ajustadas a los patrones FIFA ${ }^{8}$. Esto lleva a la resistencia de los grupos de hinchas detractores y a la adhesión e identificación de quienes legitiman estas prácticas. En el caso del running, a diferencia de los clubes deportivos, si bien las grandes marcas e industrias deben construir su público, logran fidelizarlo y fanatizarlo de manera similar que a los hinchas de fútbol: cuando logran reunir el corpus de gente, interactúan con ellos, forjan lazos y les permiten vivir experiencias que los hacen sentirse parte, acompañados de tácticas tecnológicas que generan identificación y comunidad.

El objetivo general de este trabajo ha sido abordar las tensiones e influencias que tuvieron en ese cambio de percepción tanto la mercantilización global de las sociedades (Giulianotti y Robertson, 2009) como la fanificación de las audiencias (Borda, 2012), a partir del análisis de registros de trabajo de campo realizado con hinchas de un club de fútbol y un grupo de corredores amateurs de la ciudad de Buenos Aires. Y, particularmente, problematizar el papel del consumo sobre la base del siguiente interrogante: las expectativas de consumo que rodean el espectáculo futbolístico y la práctica del running, ¿son impuestas por las instituciones deportivas o por las marcas que pretenden fidelizar a los espectadores o deportistas e interpelarlos como fanáticos, o son generadas e impulsadas por los propios sujetos según lógicas identitarias que responden a la pasión por el club y por el deporte? ¿Dónde está la agencia de los sujetos, en tanto hinchas o runners? Al confrontar las acciones de los hinchas fanáticos del fútbol y de los fanatizados por el running con las ideas de Sherry Ortner (2016), podemos indagar cómo se delinean las características de la agencia de estos actores. Podríamos pensar que hay agencia, esto es, actores que juegan con intenciones, motivaciones, habilidades e inteligencia. Ortner enfatiza el lado intencional en la

\footnotetext{
${ }^{8}$ La Federación Internacional de Fútbol Asociado (FIFA) es el organismo rector del fútbol mundial.
} 
agencia, definiéndola como una forma de propiedad de los sujetos sociales $y$, en un determinado nivel, puede también ser una forma de poder. De este modo, los "agentes" equivalen a "sujetos empoderados" que desafían las construcciones y determinaciones de la estructura. Sin embargo, el poder de expresión y libertad de los actores a la vez puede ser ilusorio ya que no son elecciones totalmente independientes sino que dependen de una serie de factores e influencias sociales, culturales y mercantiles. En este sentido, si me remito a los registros de observación de campo y al análisis de las entrevistas realizadas, podría asumir que hay influencias recíprocas: los clubes -sus dirigentes, mejor dicho- hacen uso de los sentimientos de los hinchas, fanificándolos para generar consumo y por ende ganancias, al igual que ocurre con las grandes marcas deportivas que buscan fidelizar a los corredores como clientes exclusivos de sus productos. Asimismo, como contracara, los hinchas y los deportistas hacen uso de las prácticas fanificadas para ponerlas a jugar en lógicas identitarias y, así, demostrar quién es más pasional o, en definitiva, quién es mejor hincha o mejor runner.

Ciudad Autónoma de Buenos Aires, 10 de marzo 2017

\section{Agradecimientos}

Este artículo fue realizado con el apoyo financiero del Consejo Nacional de Investigaciones Científicas y Técnicas (CONICET), en el marco de las investigaciones desarrolladas por el Seminario Permanente de Estudios Sociales del Deporte, financiado a través de los proyectos PIP 11220150100751 2016-2018, UBACyT 20020150200090BA 2016-2018 y CONICET, dirigidos por la Dra. Verónica Moreira, el Dr. José Garriga Zucal y el Dr. Pablo Alabarces.

\section{Bibliografía}

Alabarces, P. (2004). Crónicas del aguante. Fútbol, violencia y política. Buenos Aires, Argentina: Capital Intelectual.

Alabarces, P., Garriga Zucal, J. (2007). Identidades Corporales: entre el relato y el aguante. Campos, Revista de Antropología Social, 8(1), 145-166. Recuperado de http://revistas.ufpr.br/ campos/article/view/9548/6622

Baudrillard, J. (2004 [1969]). Las estructuras de colocación; Conclusión: hacia una definición del consumo. En El sistema de los objetos (pp. 13-30; 223-229). México: Siglo XXI Editores.

Bauman, Z. (2008). Cultura consumista. En Vida de consumo (pp. 115-159). Buenos Aires, Argentina: Fondo de Cultura Económica.

Borda, L. (2012). Bettymaníacos, luzmarianas y mompirris: el fanatismo en los foros de telenovelas latinoamericanas (Tesis doctoral en Ciencias Sociales). Facultad de Ciencias Sociales, Universidad de Buenos Aires, Argentina.

Bourdieu, P. (1979). La elección de lo necesario. En La distinción: Criterios y bases sociales del gusto (pp. 379-403). Madrid, España: Taurus.

De Moraes, D. (2010). Cultura tecnológica, innovación y mercantilización. En Mutaciones de lo visible (pp. 45-80). Buenos Aires, Argentina: Paidós.

García Canclini, N. (1995). El consumo sirve para pensar. En Consumidores y ciudadanos. Conflictos multiculturales de la globalización (pp. 41-55). México: Grijalbo.

Garriga Zucal, J. (2005). 'Soy macho porque me la aguanto'. Etnografía de las prácticas violentas y la conformación de las identidades de género masculino. En Alabarces, P. et al. (Comp.), Hinchadas (pp. 39-58). Buenos Aires, Argentina: Prometeo.

Giulianotti, R. (2012). Fanáticos, seguidores, fãs e flaneurs: uma taxonomia do identidades do torcedor no futebol. Revista de História do Esporte, 5(1), 25-46. Recuperado de http://www.ludopedio.com.br/v2/content/uploads/204400_ recordeV5N1_2012_11.pdf

Giulianotti, R. y Robertson, R. (2009). Globalization and Football. London, UK: Sage Publications Ltd.

Hijós, M. N. (2014). El deporte como mercancía. Un estudio sobre la dimensión económica y las múltiples lógicas en el Club Atlético Boca Juniors (Tesis de grado en Antropología). Facultad de Filosofía y Letras, Universidad de Buenos Aires, Argentina.

Martín-Barbero, J. (1983). Memoria narrativa e industria cultural. Comunicación y cultura, (10), 59-73.

Moreira, M. V. (2005). Trofeos de guerra y hombres de honor. En Alabarces, P. et al. (Comp.), Hinchadas (pp. 75-90). Buenos Aires, Argentina: Prometeo.

Moreira, M. V. (2006). Los modos de ser hincha. Participación social y proceso político en un club social y deportivo (Tesis de maestría en Antropología Social). Instituto de Desarrollo Económico y Social, Universidad Nacional de Gral. San Martín, Argentina.

Moreira, M. V. (2008). Club social y deportivo: hinchas, política y poder. En Alabarces, P. y Rodríguez, M. G. (Comps.), Resistencias y mediaciones. Estudios sobre cultura popular (pp. 113-138). Buenos Aires, Argentina: Paidós.

Moreira, M. V. (2010). La política futbolizada: Los dirigentes deportivos y las redes político-territoriales en Avellaneda (Tesis doctoral en Ciencias Sociales). Facultad de Ciencias Sociales, Universidad de Buenos Aires, Argentina.

Ortner, S. B. (2016). Antropología y teoría social: cultura, poder y agencia. Argentina: Universidad Nacional de Gral. San Martín, UNSAM EDITA.

Sassatelli, R. (2012). Consumo, cultura y sociedad. Buenos Aires, Argentina: Amorrortu.

Taylor, I. (1971a). Football mad: a speculative sociology of football hooliganism. En Dunning, E. (Ed.), The sociology of sport: A collection of readings (pp. 352-377). London, UK: Frank Cass.

Taylor, I. (1971b). Soccer consciousness and soccer hooliganism. En Cohen, S. (Ed.), Images of Deviance (pp. 134-164). Harmondsworth, UK: Penguin Books.

Villena Fiengo, S. (2003). Gol-balización, identidades nacionales y fútbol. En Alabarces, P. (Comp.), Futbologías: fútbol, identidad y violencia en América Latina (pp. 257-271). Buenos Aires, Argentina: CLACSO. 